\title{
Berdin artatzen al ditugu pazienteak emakumezko ala gizonezko izan?
}

\author{
Do we manage female and male patients equally? \\ Ainitze Labaka ${ }^{1 *} ;$ Eva Pereda-Pereda $^{1,2}$, Joana Perez Tejada ${ }^{4}$ \\ ${ }^{1}$ Erizaintza II saila, Euskal Herriko Unibertsitatea, UPV/EHU \\ ${ }^{2}$ Nortasuna, Balioespena eta Psikologia Tratamendu Saila, , UPV/EHU \\ ${ }^{3}$ Biodonostia Osasun Ikerketa Institutua; Osasun Mentala eta Arreta Psikiatrikoa, Donostia \\ ${ }^{4}$ Onkologikoa Fundazioa, Donostia \\ Laburpena \\ *ainitze.labaca@ehu.eus
}

Ikerketa epidemiologiko zein kualitatiboek adierazten dutenez, paziente bat ezberdin artatua suerta daiteke emakumezko ala gizonezko izan. Berrikuspen bibliografiko honetan, fenomeno horren atzean egon daitekeen osasun-profesionalen genero-isuri psikologikoaren nondik norakoak aztertu dira. Hainbat lurraldetako ikerketa ezberdinen emaitzak kontuan hartuz, genero-isuriak osasunprofesionalen esfortzu terapeutikoan eragin dezake, eta horrek, halaber, pazientea artatzeko, tratatzeko eta bideratzeko prozesua alda dezake, morbi-mortalitatean eraginez. Osasungintzan ageri den genero-isuria murrizteko lerro estrategiko gisara, baliabide hauek gomendatzen dira: sexuezberdintasun biologikoak errespetatzen dituzten gida kliniko estandarizatuak, osasun-profesionalen genero-kontzientzia eta aurreiritzien lanketa, eta genero-gaiak osasun-ikasketetan jorratzea.

Gako-hitzak: generoa, isuri psikologikoa, osasun-profesionala, esfortzu terapeutikoa

\section{Abstract}

Both epidemiological and qualitative research indicate that a patient can be differently treated depending on gender. This bibliographical revision aims to provide an approach of the gender bias in health professionals. Worldwide collected data suggest that gender bias affects the therapeutic effort of health professionals, and this changes, in turn, the clinical care and treatment processes, affecting the morbi-mortality rates. In order to reduce the gender bias in health care, interventions should include sex specific clinical guides, gender awareness education of health professionals and inclusion of gender-related curricula in health studies.

Keywords: gender, psychological bias, health professional, therapeutic effort

Bidalia: 2019ko apirilaren 17an.

Onartua: 2019ko urriaren 16an.

http://doi.org/10.26876/osagaiz.2.2019.253

\section{Sarrera, helburuak eta metodologia}

Laurogeita hamarreko hamarkadan lurralde ekonomikoki garatuetako osasungintzan generobereizkeria zegoela argitara atera zen, miokardioko infartu akutuaren inguruan jasotako datuen eskutik. Urteek ez dute, ordea, gizartean -eta osasungintzan - errotutako genero-isuria ezabatu, eta Osasunaren Mundu Erakundearen arabera, ertz asko ditu emakumezkoetan desabantailak eragiten dituen fenomeno horrek (1): “Emakumezkoak eta gizonezkoak ezberdinak dira haien biologian, gizarteak esleitutako roletan eta familia eta komunitateko posizioan. Horrek eragina izango 
du beren osasuna hobetzeko egiten duten esfortzuan, baita osasun-sistemak beren beharrei erantzuteko duen moduan ere".

Hori kontuan hartuta, lan honen helburua esfortzu terapeutikoan egon daitekeen genero-isuriak eztabaidagai gisa duen garrantzia azpimarratzea da, baita hura murrizteko esku-hartze esparru espezifikoak biltzea ere. Horretarako, berrikuspen bibliografiko narratiboa egin da Medline eta Dialnet datu-baseetan 2019ko urtarrila aurretik argitaratutako lanak aurkitzeko, gender bias AND therapeutic effort hitzak erabiliz. Interneteko World Health Organization (https://www.who.int/es) web-orriarekin eta ad hoc kontsultatutako Sesgos de género en la atención sanitaria gidaliburuarekin (2) osatu da informazioa.

\section{Osasun-ekitatea}

Osasunaren Mundu Erakundearen arabera, osasun-ekitatea pertsona orok bere osasun potentzial osoa lortzeko aukera zilegi izateari deritzo, bere ezaugarri sozial, ekonomiko edo demografikoengatik inolako eragozpenik jasan gabe (3).

Badira ia hiru hamarkada emakumezkoei gizonezkoen aldean proba diagnostiko gutxiago egiten zitzaizkiela eta diagnostiko berantiarra jasotzen zutela argitara eman zela (4). Zentzu horretan, UNESCOren 2014-2021 Genero Berdintasunerako Lehentasunezko Ekintza Plana edota Zientzia, Teknologia eta Berrikuntzari buruzko ekainaren 1eko 14/2011 legea emakumezkoek osasunzerbitzuak jasotzeko dituzten desabantailak gainditzera bideratuta daude, baina estatistikek adierazten dutenez, emakumezkoek artatze eraginkorra jasotzeko aukera gutxiago dute oraindik ere $(5,6)$. Datu horien atzean osasun-profesionalen genero-aurreiritzi eta -estereotipoak, sexuezberdintasun fisiologikoekiko ezjakintasuna eta genero-kontzientzia murritza egon daitezke.

Historikoki, ikerketa kliniko zein preklinikoak animalia arrekin eta gizonezkoekin osatu dira. Besteak beste Elikagai eta Sendagaien Elkarteak (FDA) eta Estatu Batuetako Osasun Institutuak (NIH) ikerlanetan bi sexuak aintzat har daitezen arautu bazuten ere, egun ez da ar eta emeen arteko proportzio parekiderik betetzen (7). Osasungintza beraz, literatura zientifiko androzentrikoaren gainean eraiki da, gorputz emearen ikerkuntza ugal-aparatura mugatuz. Izan ere, uste zen ugalketasistemako zelulak soilik ezberdintzen zirela sexuaren arabera, gainerako zelula eta sistema biologikoak berdin-berdinak zirela emakumezko nahiz gizonezko izan. Gaur egun berezitasun sexualak zelula-mailatik hasi eta hodi-sistema edo arnas aparatua bezalako egitura konplexuetara heltzen direla jakin badakigu ere, osasun-zientzien eraikuntza historiko androzentrikoak gaur egungo praktikan eragiten du. Hori dela-eta, osasungintzan emakumezkoak "konplexu"tzat edo "ezegonkor"tzat hartu izan dira, eta haien sintomatologia "atipiko"tzat, haien gaixotasun-prozesua sarri ez datorrelako gidaliburuekin bat, azken horiek gizonezkoetan oinarrituak baitira (2).

Horrela, bada, emakumezkoen sintoma, zeinu, kexu eta eskaeren aurrean, osasun-profesionalen ziurgabetasunarekiko tolerantzia-faltak eta genero-aurreiritziek praktika kliniko inkoherenteari bide eman diezaiokete $(8,9)$. Norvegiako Unibertsitate Ospitalean erizain eta medikuei egindako elkarrizketa ez-egituratuek adierazi zutenez, osasun-profesionalek paziente emakumezkoak gizonezkoen aldean eskatzaileagoak direla deritzote, hau da, arreta-denbora gehiago hartzen dutela eta behar dutena baino informazio gehiago eskatzen dutela (10). Baliteke pertzepzio horrek generoaurreiritziekin zerikusia edukitzea. Ildo horretatik, medikuak arretatsuak izan daitezke estereotipatutako genero-rolekin bat datozen kexuekin, baina ez genero-rolarekin bat ez datozenekin (11). Arrazoibide-diferentzia horrek genero-ezberdintasunak ekar ditzake prebentzioan eta tratamenduan (12). Adibidez, mina duten emakumezkoek analgesia jasotzeko aukera gutxiago dute (13). Izan ere, somatizazioari buruzko irudikapen kognitiboa gehiago erlazionatzen da emakumezkoen estereotipoarekin, eta ondorioz, osasun-profesionalek emakumezkoen mina gutxiets dezakete (14). Profesionalek ezagutza edo interpretazio okerrek bultzatuta errealitatea modu distortsionatuan prozesatu eta erabaki edo epai bidegabeak egiteko efektu psikologiko horri isuri kognitiboa deritzo (15). 


\section{Genero-isuria eta esfortzu terapeutikoa}

Tratamendu bat jasotzeko edota osasun-zerbitzuek artatua izateko emakumezkoen eta gizonezkoen arteko bereizkeria gertatzen denean agertzen da osasun-zerbitzuetako genero-isuria, betiere tratuezberdintasun hori osasun-egoerak edo sexu-ezberdintasun fisiologikoek justifikatzen ez badute (2, 16). Depresioa (17), osteoporosia eta bularreko minbizia (18) bezalako gaixotasun feminizatuetan osasun-profesionalen genero-isuriak gaitza ez diagnostikatzea eragin eta gizonezkoak kaltetu baditzake ere, oro har, emakumezkoei eragiten dien fenomenoa da, eta honako egoeretan bistaratzen da: profesionalek emandako aholkuetan, diagnostikoa egitean, tratamenduan, finkatutako zainketa estandarretan eta osasun-profesionalak protokoloekiko izan duen atxikimenduan. Isuri psikologikoek genero-ezberdintasunak eragin ditzakete osasun-ekintzen esparru hauetan (19):

\section{Osasun-profesionalaren eta pazientearen arteko} harremana

\section{Prozesu diagnostikoa}

- Gizabidezko tratua.

- Sintomen sinesgarritasuna.

- Sintomen zilegitasuna.
- Kontsultatu arteko latentzia.

- Diagnostikatua izan arteko latentzia.

- Egindako proba diagnostikoen kopurua eta agresibitatea.

\section{Prozesu terapeutikoa}

- Tratamendua hasi arteko latentzia.

- Aukeratutako tratamendu mota.

- Aukeratutako tratamenduaren pauta eta dosia.

- Albo-ondorioak kontuan hartzea.

- Albo-ondorioen inguruko kexuen sinesgarritasuna eta zilegitasuna.

\section{Prebentzioa eta jarraipena}

- Arriskuaren eta prebentzioa/jarraipena egiteko beharraren balioespena.

- Erabilitako prebentzio-prozeduren kopurua eta agresibitatea.

- Jarraipen-bisiten kopurua.

- Pazientearen autonomia.

Isuri horien ondorioak osasun-emaitza-okerragoak, konplikazio gehiago, morbilitate handiagoa eta hilkortasun-ratio handiagoa izan daitezke (20).

\section{Ondorio kaltegarriak zifretan}

Ikerketa epidemiologiko eta klinikoek pazienteen generoaren araberako osasun-zerbitzuen eraginkortasun ezberdina aurkitu dute hamaika esparrutan. Adibidez, arazo dermatologiko berdinen aurrean, gizonezko gehiagok jaso zuen tratamendua emakumezkoekin konparatuta Stockholmen (21). Suedian, diabetes mellitusa duten gizonezkoen \% 85ek jasotzen ditu ahozko antihipergluzemikoak emakumezkoen \% 55en aldean (22). Protokoloak minik gabeko makrohematuriaren aurrean pazientea onkologoarenera bideratzeko agintzen badu ere, emakumezkoen erdiak ere ez dituzte bideratzen gizonezkoen portzentajearekin konparatuta $(23,24)$. Ingalaterran 26.000 parte-hartzaile kontuan izanda egindako ikerketa baten arabera, osteoartritisa dela-eta aldaka ordezteko beharra zuten pazienteetan, emakumezkoek probabilitate gutxiago zuten espezialistarenera bideratuak izateko eta ondorengo ebakuntzarako itxaron-zerrendan sartzeko (25). Mediku zein erizainek lehenago tratatzen dituzte gizonezkoak opioideekin emakumezkoak baino (26). Bihotzeko gaixotasunen inguruan, emakumezkoak artatzerakoan eraginkortasun txikiagoa aurkitu da hainbat esparrutan: bularreko minarekin ingresatzen denetik elektrokardiograma egin bitarteko denbora luzeagoa da $(27,28)$, arrisku kardiobaskularra maneiatzeko medikazio gutxiago preskribatzen zaie (29) eta miokardioko infartuaren diagnostikoa berantiarragoa izaten da (30,31). Kanadan aurkitu zutenez, hilgarriak izan zitezkeen traumatismodun emakumezkoak gutxiagotan bideratzen ziren traumatologia-zerbitzuetara (32). Adibide horiek guztiak kontuan hartuta, 
azpimarratzekoa da pazientearen osasun-arazoa azkar ez hautemateak eta behar den zerbitzura ez bideratzeak hilkortasun-tasa handitzen duela (33).

\section{Euskadin zer?}

Osasun-profesionalek esfortzu terapeutikoan izan dezaketen isuria komunitateko kulturaren eta genero-kontzientziaren araberakoa izan daiteke. Gai horren inguruan Euskal Autonomia Erkidegoko (EAE) osasungintzan egindako ikerketak gutxi badira ere, esfortzu terapeutikoan ezberdintasunak daudela adierazten dute datuek.

Hasteko, estatu mailan, emakumezkoek bisita diagnostikoa egin arte itxaron beharreko denbora gizonezkoena baino \% 13,6 handiagoa da batez beste (34), eta lan ordaindua duten pertsonen artean, osasun-egoera bera izanda ere, baja gutxiago ematen zaie emakumezkoei gizonezkoei baino (35). Bestetik, Arabako lehen mailako osasun-arretan, II. motako diabetesa duten gizonezkoek dietaren inguruko aholku gehiago jasotzen dituzte emakumezkoek baino (36). EAEn 2002. urtean, miokardioko infartu akutu (MIA) konparagarria (sexuaren araberako ezberdintasunik ez sintoma, elektrokardiograma eta entzima mailetan) izan zuten emakumezko eta gizonenezkoen artean, emakumezkoekin esfortzu terapeutiko txikiagoa egiten zela ikusi zen, desabantaila izan baitzuten Zainketa Intentsiboetarako Unitatera sartzeko, tronbolisia jasotzeko (gizonezkoen \% 33ri vs emakumezkoen \% 24ri), eta angioplastia (gizonezkoen \% 48ri vs emakumezkoen \% 29ri) eta kateterismoa egiteko (gizonezkoen \% 10i vs emakumezkoen \% 6ri) (37). Ordutik urte asko pasa badira ere, eta EAEn MIA duten pazienteak artatzeko protokolo bateratua finkatu bada ere, gizonezkoekin alderatuta MIA jasaten duten emakumezkoek tratamendu egokia jasotzeko aukera gutxiago edukitzen jarraitzen dute, nahiz eta arrakala txikitu den (38). Psikofarmakoen preskripzioaren inguruan egindako ikerketa kualitatibo baten arabera, osasun-arazo berberen aurrean, emakumezkoen ahultasunaren inguruko sinesmen ideologikoak balorazio ezberdina eginarazten zien hainbat autonomia-erkidegotako medikuei, Euskadi tarteko (39).

Badirudi, beraz, genero-ikuspuntua kontuan hartzen duten gida kliniko eta protokoloak finkatzeak ez duela erabateko eraginkortasunik osasun-profesionalen praktikan. Litekeena baita gaixotasunen sexu-ezberdintasunen inguruko ezjakintasunaz gain, gizartean eta, beraz, osasun-profesional askorengan errotutako genero-aurreiritziek eragina izatea.

\section{Genero-isuria osasun-profesionalen formazioan}

Zenbait adituren esanetan, osasun-sistemako genero-isuria profesionalen formazioan eta heziketan genero-gaiei esku hartuz saihestuko litzateke $(16,20,40)$. Horretarako, jarrera, aurreiritzi eta estereotipoak landu beharko lirateke, eta ikasleei beren interpretazio propioen eta besteenen inguruan hausnartzeko aukera eman beharko litzaieke, kasu kliniko eta rol-jokoak landuz adibidez (16). Gainera, anatomia bezalako irakasgaietan tradizionalki erabilitako eredu eta liburuak aztertu eta birplanteatu beharko lirateke. Izan ere, osasungintzak teorian asexuatu zeritzon (bi sexuak ordezkatzeko erabilgarria) gorputz-eredu bat erabili izan du, baina benetan erabat androzentrikoa zena. Horrela, gorputz maskulinoa izan da gizakiaren ordezkari unibertsala, gorputz femeninoa ugalkortasunaz gaindiko aspektuetan ikusezin bihurtuz. Horrek osasun-profesionalen pertzepzio klinikoa sexu- eta genero-ezberdintasunekiko sentikorra izatea zaildu du (41).

Heziketan gai hauek jorratzeko zenbait erresistentzia aurkitu izan dira ordea: ikasketen curriculumeko gainkarga, soilik emakumezkoen intereseko gaia delako ustea, autoritate akademikoen aurrean genero-isuria identifikatzeko zailtasuna eta, beraz, zentroetan aldaketapolitika sustatzeko oztopoak. Laburbilduz, unibertsitate-tituluetan genero-perspektiba txertatzeko gakoa maila politikoan, antolamendu-mailan, kultura-aldaketan eta irakaslerian datza (42). 


\section{Genero-erlazioak osasungintzan}

Paradoxa badirudi ere, osasun-profesionalen genero-isuriaren ikerketak berak ere, genero-isuria erakutsi du bere baitan. Izan ere, medikuei edo medikuntzako ikasleei soilik pasa zaizkie generokontzientziaren inguruko galdetegiak eskuarki $(40,43,44)$, erizainak ere osasun-profesionalak direla eta haien aurreiritziek ere pazientearengan eragin zuzena dutela ahaztuz. Lanbide feminizatua izaki, erizaintza-zainketak historikoki emakume zaintzailearen irudiarekin erlazionatu dira, eta erizaintza medikuntzaren pean egon da. Bi aspektu horiek generoari estuki loturiko osagaiak dituzte. Medikuen eta erizainen arteko botere-harremanak emakumezkoen eta gizonezkoen hierarkizazioa sinbolikoki erreproduzitu dezakeela iradoki da (45), erizainek beren profesioagatiko errekonozimendu soziala jasotzea eragotziz. Erizaintzak azken urteetan autonomia handia irabazi badu ere, bere funtzioak ikusezina izaten jarraitzen du aditu batzuen esanetan (46). Erizainek edozein osasun-sistematako plantillaren gehiengoa osatzen dutela kontuan hartuta, eta mina bezalako sintometan esku-hartzean genero-isuria izan dezaketela aurkitu dela jakinda (46), kalitatezko osasungintzako profesional aktibo bezala duten potentziala gutxiestea akatsa litzake.

Laburbilduz, osasun-profesionalen genero-isuriak pazienteen morbi-mortalitatean eragina izan dezake, eta badirudi EAEn ere gertatzen den fenomenoa dela. Ekitatea helburu, genero-isuria murrizteko askotariko estrategiak jar daitezke martxan, hala nola sexu-ezberdintasun biologikoak errespetatzen dituzten gida kliniko estandarizatuak erabiltzea, osasun-profesionalen generokontzientzia eta aurreiritziak lantzea eta genero-gaiak erizaintza eta medikuntzako ikasketetan jorratzea.

\section{Bibliografia}

1. World Health Organization. Women's health and well-being in Europe: beyond the mortality advantage [Internet]. Danimarka: WHO Regional Office for Europe; 2016 [Kontsulta: 2019-0203]. Eskuragarri:

http://www.euro.who.int/ data/assets/pdf file/0006/318147/EWHR16 interactive2.pdf?u $\underline{a=1}$

2. Ruiz-Cantero MT. Sesgos de género en la atención sanitaria. Granada: Escuela Andaluza de Salud Pública; 2009.

3. World Health Organization. Health equity [Internet]. Geneva: World Health Organization; 2017 [Kontsulta: 2019-01-16]. Eskuragarri: https://www.who.int/topics/health equity/en/

4. Healy B. The Yentl Syndrome [Internet]. N Engl J Med. 1991 [Kontsulta: 2019-01-16]. Uzt 25; 325(4):274-276. Eskuragarri: http://dx.doi.org/10.1056/NEJM199107253250408

5. Bonita R, Beaglehole R. Women and NCDs: overcoming the neglect [Internet]. Glob Health Action. 2014 [Kontsulta: 2019-01-15]; 7:23742. Eskuragarri: https://www.tandfonline.com/doi/full/10.3402/gha.v7.23742

6. Langer A, Meleis A, Knaul FM, Atun R, Aran M, Arreola-Ornelas H, Bhutta ZA, Binagwaho A, Bonita R, Caglia JM, Claeson M, Davies J, Donnay FA, Gausman JM, Glickman C, Kearns AD, Kendall T, Lozano R, Seboni N, Sen G, Sindhu S, Temin M, Frenk J. Women and Health: the key for sustainable development [Internet]. Lancet. 2015 [Kontsulta: 2019-01-28]; 386(9999):1165-1210. Eskuragarri: https://linkinghub.elsevier.com/retrieve/pii/S0140673615604974

7. Prager EM. Addressing sex as a biological variable. J Neurosci Res. 2017;95(1-2):11.

8. Bernard AM, Hayward RA, Rosevear JS, McMahon LF. Gender and hospital resource use: Unexpected differences [Internet]. Eval Health Prof. 1993 [Kontsulta: 2019-01-21]; 16(2):177-89. Eskuragarri: http://journals.sagepub.com/doi/10.1177/016327879301600203

9. McPherson K. Why do variations occur? Mooney $\mathrm{G}$, Anderson $\mathrm{T}$, argitaratzaileak. The challenges of medical variations. Economic Issues in Health Care. London: McMillan; 1990; 16-35. Orrialdeak.

10. Foss C, Sundby J. The construction of the gendered patient: hospital staff's attitudes to female and male patients. Patient Educ Couns. 2003;49(1):45-52. 
11. Floyd BJ. Problems in accurate medical diagnosis of depression in female patients [Internet]. Soc Sci Med. 1997 [Kontsulta: 2019-01-28]; 44(3):403-412. Eskuragarri: http://www.ncbi.nlm.nih.gov/pubmed/9004374

12. Benrud LM, Reddy DM. Differential explanations of illness in women and men [Internet]. Sex Roles. 1998 [Kontsulta: 2019-01-28]; 38(5-6):375-386. Eskuragarri: http://link.springer.com/10.1023/A:1018753720941

13. Mogil JS. Perspective: equality need not be painful [Internet]. Nature. 2016 [Kontsulta: 201901-15]; 535(7611):S7. Eskuragarri: http://dx.doi.org/10.1038/535S7a

14. Bernardes SF, Lima ML. A contextual approach on sex-related biases in pain judgements: the moderator effects of evidence of pathology and patients' distress cues on nurses' judgements of chronic low-back pain [Internet]. Psychol Health. 2011; 26(12):1642-1658. Eskuragarri: https://www.tandfonline.com/doi/pdf/10.1080/08870446.2011.553680?needAccess=true

15. Kahneman D, Tversky A. Subjective probability: a judgment of representativeness [Internet]. Cogn Psychol. 1972 [Kontsulta: 2019-01-21]; 3(3): 430-454. Eskuragarri: https://www.sciencedirect.com/science/article/pii/0010028572900163

16. Hamberg K. Gender bias in medicine [Internet]. Women's Heal. 2008; 4(3):237-243. Eskuragarri: https://journals.sagepub.com/doi/pdf/10.2217/17455057.4.3.237

17. Krumm S, Checchia C, Koesters M, Kilian R, Becker T. Men's views on depression: a systematic review and metasynthesis of qualitative research. Psychopathology. 2017;50(2):107-124.

18. Baggio G, Corsini A, Floreani A, Giannini S, Zagonel V. Gender medicine: a task for the third millennium. Clin Chem Lab Med. 2013;51(4):713-727.

19. Tasa-Vinyals E, Mora Giral M RR. Sesgo de género en medicina. Concepto y estado de la cuestión. [Internet]. Cuad Med Psicosomática y Psiquiatr Enlace. 2015 [Kontsulta: 2019-0611];(113):14-25. Eskuragarri: https://dialnet.unirioja.es/servlet/articulo?codigo=5207966

20. Risberg G, Johansson EE, Hamberg K. A theoretical model for analysing gender bias in medicine [Internet]. Int J Equity Health. 2009 [Kontsulta: 2019-01-28]; 8(1):28. Eskuragarri: http://equityhealthj.biomedcentral.com/articles/10.1186/1475-9276-8-28

21. Osika I, Evengård B, Waernulf L, Nyberg F. [The laundry-basket project--gender differences to the very skin. Different treatment of some common skin diseases in men and women] [Internet]. Lakartidningen. 2005 [Kontsulta: 2019-01-28]; 102(40):2846-8, 2850-1. Eskuragarri: http://www.ncbi.nlm.nih.gov/pubmed/16255359

22. Brännström J, Hamberg K, Molander L, Lövheim H, Gustafson Y. Gender disparities in the pharmacological treatment of cardiovascular disease and diabetes mellitus in the very old [Internet]. Drugs Aging. 2011 [Kontsulta: 2019-01-28]; 28(12):993-1005. Eskuragarri: http://www.ncbi.nlm.nih.gov/pubmed/22117097

23. Rachet $B$, Maringe $C$, Nur U, Quaresma $M$, Shah A, Woods LM, Ellis L, Walters S, Forman D, Steward J, Coleman MP. Population-based cancer survival trends in England and Wales up to 2007: an assessment of the NHS cancer plan for England [Internet]. Lancet Oncol. 2009 [Kontsulta: 2019-01-28]; 10(4):351-369. Eskuragarri: http://www.ncbi.nlm.nih.gov/pubmed/19303813

24. Joshi SS, Handorf ER, Smaldone MC, Geynisman DM. What can the National Cancer Database tell us about disparities in advanced bladder cancer outcomes? [Internet]. Transl Androl Urol. 2018 [Kontsulta: 2019-01-28];7(4):732-735. Eskuragarri:

http://www.ncbi.nlm.nih.gov/pubmed/30211063

25. Jüni P, Low N, Reichenbach S, Villiger PM, Williams S, Dieppe PA. Gender inequity in the provision of care for hip disease: population-based cross-sectional study [Internet]. Osteoarthr Cartil. 2010 [Kontsulta: 2019-01-28]; 18(5):640-645. Eskuragarri: http://www.ncbi.nlm.nih.gov/pubmed/20167302

26. Wandner LD, Heft MW, Lok BC, Hirsh AT, George SZ, Horgas AL, Atchison JW, Torres CA, Robinson ME. The impact of patients' gender, race, and age on health care professionals' pain management decisions: an online survey using virtual human technology [Internet]. Int J Nurs Stud. 2014 [Kontsulta: 2019-01-28]; 51(5):726-733. Eskuragarri: http://www.ncbi.nlm.nih.gov/pubmed/24128374 
27. Valentin A, Jordan B, Lang T, Hiesmayr M, Metnitz PG. Gender-related differences in intensive care: a multiple-center cohort study of therapeutic interventions and outcome in critically ill patients [Internet]. Crit Care Med. 2003 [Kontsulta: 2019-01-28]; 31(7):19011907. Eskuragarri: http://www.ncbi.nlm.nih.gov/pubmed/12847381

28. Mahmood K, Eldeirawi K, Wahidi MM. Association of gender with outcomes in critically ill patients [Internet]. Crit Care. 2012 [Kontsulta: 2019-01-28]; 16(3):R92. Eskuragarri: http://www.ncbi.nlm.nih.gov/pubmed/22617003

29. Abuful A, Gidron Y, Henkin Y. Physicians' attitudes toward preventive therapy for coronary artery disease: is there a gender bias? [Internet]. Clin Cardiol. 2005 [Kontsulta: 2019-01-28]; 28(8):389-393. Eskuragarri: http://www.ncbi.nlm.nih.gov/pubmed/16144216

30. Bösner S, Haasenritter J, Hani MA, Keller H, Sönnichsen AC, Karatolios K, Schaefer JR, Baum E, Donner-Banzhoff N. Gender bias revisited: new insights on the differential management of chest pain [Internet]. BMC Fam Pract. 2011 [Kontsulta: 2019-01-28]; 12-45. Eskuragarri: http://www.ncbi.nlm.nih.gov/pubmed/21645336

31. Chang AM, Mumma B, Sease KL, Robey JL, Shofer FS, Hollander JE. Gender bias in cardiovascular testing persists after adjustment for presenting characteristics and cardiac risk [Internet]. Acad Emerg Med. 2007 [Kontsulta: 2019-01-28]; 14(7):599-605. Eskuragarri: http://www.ncbi.nlm.nih.gov/pubmed/17538080

32. Gomez D, Haas B, de Mestral C, Sharma S, Hsiao M, Zagorski B, Rubenfeld G, Ray J, Nathens AB. Gender-associated differences in access to trauma center care: A population-based analysis [Internet]. Surgery. 2012 [Kontsulta: 2019-01-28]; 152(2):179-185. Eskuragarri: http://www.ncbi.nlm.nih.gov/pubmed/22727364

33. Haas B, Stukel TA, Gomez D, Zagorski B, De Mestral C, Sharma SV, Rubenfeld GD, Nathens AB. The mortality benefit of direct trauma center transport in a regional trauma system [Internet]. J Trauma Acute Care Surg. 2012 [Kontsulta: 2019-01-28]; 72(6):1510-1517. Eskuragarri: http://www.ncbi.nlm.nih.gov/pubmed/22695414

34. Abásolo I, Negrín-Hernández MA, Pinilla J. Equity in specialist waiting times by socioeconomic groups: Evidence from Spain. [Internet]. Eur J Heal Econ. 2014;15(3):323-334. Eskuragarri: https://link.springer.com/content/pdf/10.1007\%2Fs10198-013-0524-x.pdf

35. Ruiz-Cantero MT, Vives-Cases C, Artazcoz L, Delgado A, García Calvente MM, Miqueo C, Montero I, Ortiz R, Ronda E, Ruiz I, Valls C. A framework to analyse gender bias in epidemiological research [Internet]. J Epidemiol Community Health. 2007 [Kontsulta: 201901-28]; 61(Suppl 2):ii46-ii53. Eskuragarri: http://www.ncbi.nlm.nih.gov/pubmed/18000118

36. Bacigalupe A, Esnaola S, Fraile I, Ibarra J, Urraca J, Sánchez S, Millán E. Gizartedesberdintasunak 2 motako diabetesaren arretan Arabako Eskualdean [Internet]. VitoriaGasteiz: Osasun Saila, Azterlan eta Ikerkuntza Sanitarioko Zerbitzua; 2017 [Kontsulta: 201902-03]. Eskuragarri:

https://www.osakidetza.euskadi.eus/contenidos/informacion/publicaciones informes estud io/eu pub/adjuntos/diabetes eu.pdf

37. Larrañaga N, Basterretxea M. Infarto agudo de miocardio con ingreso hospitalario en Gipuzkoa. Gac Sanit. 2002;16(1): 16-25.

38. Telleria M, Loma A, Artaecheverria J, San Roman KG, Rumoroso JR, Andres A, Vazquez P, Oria C. Miokardioko infartu akutuen maneiua Euskal Autonomia Erkidegoan (EAE) sexuaren arabera, Bihotzez sarearen eragina [Internet]. Osagaiz 2017 [Kontsulta: 2019-01-29]; 1(1):1625. Eskuragarri: http://www.osagaiz.eus/article/download/183/218

39. Gil García E, Romo Avilés N, Poo Ruiz M, Meneses Falcón C, Markez Alonso I, Vega Fuente A. Género y psicofármacos: la opinión de los prescriptores a través de una investigación cualitativa [Internet]. Atención Primaria.2005 [Kontsulta 2019-06-11];35(8):402-407. Eskuragarri: https://linkinghub.elsevier.com/retrieve/pii/S021265670570384X

40. Verdonk P, Benschop YWM, De Haes HCJM, Lagro-Janssen TLM. Medical students' gender awareness: Construction of the Nijmegen gender awareness in medicine scale (N-GAMS) [Internet]. Sex Roles. 2008; 58(3-4):222-234. Eskuragarri: https://link.springer.com/content/pdf/10.1007\%2Fs11199-007-9326-x.pdf

41. Vázquez-Santiago S, Garrido Peña F. El enfoque de género en las necesidades de atención sociosanitaria [Internet]. Enferm Clin. 2016 [Kontsulta: 2019-01-29]; 26(1):76-80. 
Eskuragarri: https://www.elsevier.es/es-revista-enfermeria-clinica-35-pdf$\underline{\mathrm{S} 1130862115001217}$

42. Ruiz-Cantero MT, Tomás-Aznar C, Rodríguez-Jaume MJ, Pérez-Sedeño E, Gasch-Gallén Á. Agenda de género en la formación en ciencias de la salud: experiencias internacionales para reducir tiempos en España [Internet]. Gac Sanit. 2018 [Kontsulta: 2019-01-29]; prentsan. Eskuragarri: https://www.sciencedirect.com/science/article/pii/S0213911118301092?via\%3Dihub

43. Parker RB, Parker PD, Larkin T, Cockburn J. A psychometric evaluation of the gender bias in medical education scale [Internet]. BMC Med Educ. 2016 [Kontsulta: 2019-01-28]; 16(1):1-9. Eskuragarri: http://dx.doi.org/10.1186/s12909-016-0774-2

44. Salgado DM, Vogt DS, King LA, King DW. Gender Awareness Inventory-VA: A measure of ideology, sensitivity, and knowledge related to women veterans' health care [Internet]. Sex Roles. 2002 [Kontsulta: 2019-01-28];46(7-8):247-262. Eskuragarri: http://link.springer.com/10.1023/A:1020171416038

45. Arroyo Rodríguez A, Lancharro Tavero I, Romero Serrano R, Morillo Martín MS. La Enfermería como rol de género [Internet]. Index de Enfermería. 2011 [Kontsulta: 2019-01-28]; 20(4):248-251. Eskuragarri: http://scielo.isciii.es/scielo.php?script=sci arttext\&pid=S1132$12962011000300008 \& \operatorname{lng}=e n \& n r m=i s o \& \operatorname{lng}=e n$

46. Galbany-Estragués P, Comas-d'Argemir D. Care, autonomy, and gender in Nursing practice: A historical study of nurses' experiences. J Nurs Res. 2 